\title{
Heats of Combustion and Isomerization of
}

\section{Six Pentadienes and Spiropentane}

\author{
Frances Maron Fraser and Edward J. Prosen
}

\begin{abstract}
The heats of combustion of six pentadienes and spiropentane were measured by combustion of the hydrocarbon vapors, carried by helium gas, in a flame at constant pressure; the reaction was carried out in a glass reaction vessel contained in a calorimeter. The calorimeter system was calibrated by means of electric energy.

The experimental data yielded the following values for the standard heat of combustion, $-\Delta H c^{\circ}$, at $25^{\circ} \mathrm{C}$ and constant pressure, of the gaseous hydrocarbon in gaseous oxygen to form gaseous carbon dioxide and liquid water, with all the reactants and products in their thermodynamic standard reference states, in kilocalories per mole, where $1 \mathrm{kcal}=4.1840 \mathrm{kj}$ : 1,2-pentadiene, $\quad 777.14 \pm 0.15 ; \quad 1$,cis-3-pentadiene, $\quad 763.30 \pm 0.21 ; \quad 1$,trans-3-pentadiene, $761.64 \pm 0.15 ; 1,4$-pentadiene, $768.94 \pm 0.30 ; 2,3$-pentadiene, $775.32 \pm 0.16 ; 2$-methyl-1,3butadiene (isoprene), $761.62 \pm 0.23$; spiropentane, $787.77 \pm 0.17$.

From the above data the heats of isomerization to isoprene in kilocalories per mole were calculated to be 2 -methyl-1,3-butadiene (isoprene) $=0 ; 1,2$-pentadiene $=-15.52 \pm 0.23$; 1 , cis-3-pentadiene $=-1.68 \pm 0.27 ; \quad 1$,trans-3-pentadiene $=-0.02 \pm 0.22 ; \quad 1,4$-pentadiene $=$ $-7.32 \pm 0.34 ; 2,3$-pentadiene $=-13.70 \pm 0.23 ;$ spiropentane $=-26.14 \pm 0.24$.

Values of the heats of formation and hydrogenation were also derived from these data.
\end{abstract}

\section{Introduction}

This investigation is a continuation of the program on thermochemistry of monomers and related compounds $[1,2,3,4]^{1}$ sponsored by the Office of Synthetic Rubber of the Federal Facilities Corporation. It also forms a part of the work of the Thermochemical Laboratory of the National Bureau of Standards on the determination of heats of formation of compounds of importance to industry and science [5].

Calorimetric measurements have been made of the heats of combustion at constant pressure of isoprene and six of its isomers of empirical formula $\mathrm{C}_{5} \mathrm{H}_{8}$. Values of heats of isomerization, formation, and hydrogenation are derived from these data.

These data are useful in the calculation of heats of other reactions involving these compounds and, in addition, the data are precise and accurate enough to yield valuable information on relations between energy content and structure of molecules and, together with thermodynamic functions, yield equilibrium constants of important reactions, such as isomerization, hydrogenation, etc.

\section{Method and Apparatus}

The unit of energy is the absolute joule. For conversion to the conventional thermochemical calorie, the following relation was used: $1 \mathrm{cal}=4.1840$ abs j.

The molecular weight of carbon dioxide upon which the amounts of reaction in these experiments were based was taken as 44.010 from the 1952 table of international atomic weights [6].

The heats of combustion of the seven compounds reported in this investigation were determined by

\footnotetext{
Figures in brackets indicate the literature references at the end of this paper.
}

the method described previously [1,2] for gaseous hydrocarbons. As the present compounds are normally liquids at room temperature, the vapors were passed into the calorimeter by use of helium gas as a carrier.

Briefly, the method consists in determining in one set of experiments the energy equivalent, $E_{s}$, of the calorimeter system by measuring the electric energy supplied to the calorimeter heater to produce a 4-deg $\mathrm{C}$ rise in the temperature of the calorimeter. In another set of experiments, roughly the same 4-deg $\mathrm{C}$ rise in the temperature of the calorimeter is produced by the chemical energy of combustion of the hydrocarbon in oxygen in a flame; the reaction is carried out in the glass reaction vessel contained in the calorimeter. Thus, the calorimeter is simply used as a comparator of the two types of energy.

The calorimeter assembly, thermometric system, reaction vessel, sparking system, and electric-energy measuring apparatus have been described previously $[1,2]$. However, several improvements have been made in the apparatus and procedure.

In the sparking system [1], the four dry cells previously used as a source of energy were replaced during the course of these experiments by a $6-\mathrm{V}$ storage battery. This produced a more constant sparking energy over long periods of time.

The present compounds are liquids at room temperature, $25^{\circ} \mathrm{C}$, with boiling points ranging from $26^{\circ}$ to $48^{\circ} \mathrm{C}$. To introduce the vapors into the calorimeter, helium was bubbled through the liquid hydrocarbon with the bubbler and liquid maintained at some constant temperature below room temperature in the range $19^{\circ}$ to $24^{\circ} \mathrm{C}$. A very steady and efficient flame was easily produced, even though, in some cases, a fairly large percentage of helium was passed in with the hydrocarbon.

An improvement was made in the method of 
switching the hydrocarbon gas or hydrocarbonhelium gas mixture into the calorimeter from the bypass line. Previously $[1,2]$ the hydrocarbon rate was set through a bypass line, and the pressure in this line was somewhat lower than the pressure inside the reaction vessel with oxygen flowing through it. In order to avoid backflow of oxygen into the hydrocarbon line when the hydrocarbon was turned into the vessel, it was necessary to hold back the hydrocarbon for a few seconds to build up a back pressure slightly larger than the pressure in the vessel. This was also desirable because the slightly higher pressure thus built up in the hydrocarbon line made the hydrocarbon reach the burner tip more rapidly, and thus the time required for sparking was shorter than it would otherwise be. This method proved to be irreproducible and tended to produce a large initial flame, which then decreased in size until a steady flow established itself. When hydrocarbon-helium mixtures were used, this method was particularly cumbersome. These difficulties were avoided by installing a differential mercury manometer between the hydrocarbon bypass line and the hydrocarbon line leading into the reaction vessel. With a needle valve at the end of the bypass line, it was then a simple matter to produce a steady pressure in the bypass line about $1 \mathrm{~mm}$ of mercury higher than the pressure in the vessel. When the hydrocarbon or hydrocarbon-helium mixture was then turned into the reaction vessel, the rate was steady, and the hydrocarbon reached the burner tip in the same number of seconds in each experiment.

\section{Materials and Procedure}

The pentadienes used in the present experiments were NBS Standard Samples with the following amounts of impurities in mole percent: 1,2-pentadiene, $0.34 \pm 0.15 ; 1$,cis-3-pentadiene, $0.08 \pm 0.04$; 1,trans-3-pentadiene, $0.08 \pm 0.03 ; 1$,4-pentadiene, $0.07 \pm 0.05 ; 2,3$-pentediene, $0.15 \pm 0.07$; and 2 methyl-1,3-butadiene (isoprene), $0.04 \pm 0.03$. The purification and determination of purities of these pentadienes, by the freezing-point method, are described by Streiff, Soule, Kennedy, Janes, Sedlak, Willingham, and Rossini [7] for their API-Standard lots.

The spiropentane was obtained from G. Waddington of the Thermodynamics Laboratory, Petroleum Experiment Station, Bureau of Mines. The purification and determination of purity, by the calorimetric freezing-point method, are described by Scott, Finke, Hubbard, McCullough, Gross, Williamson, Waddington, and Huffman [8] for their sample C. The purity was 99.87 mole percent.

It is believed that in each case the impurity was predominately isomeric and present in such small amount that the heat of combustion was not affected in the worst case by more than one-half the estimated uncertainty of the final results listed in tables 3 , 4 , and 5 .

The oxygen used for combustion and the helium used as a carrier gas were freed of combustible im- purities by passage through copper oxide at about $550^{\circ} \mathrm{C}$. They were then freed of carbon dioxide and water before entering the calorimeter or bubbler by passage through tubes containing successively ascarite, magnesium perchlorate, and phosphorus pentoxide.

Samples of the products of combustion were analyzed, by means of indicator tubes [9] for carbon monoxide, the most likely product of incomplete combustion, and mass spectrometrically for other products of incomplete combustion by the Gas Chemistry Section of the Bureau. In no case was the total amount of carbon monoxide greater than 0.005 percent of the amount of carbon dioxide formed in the combustion. No other products of incomplete combustion were found by mass spectrometer analysis; hence no corrections were applied for incomplete combustion.

For each calorimetric combustion experiment, the amount of reaction was determined from the mass of carbon dioxide formed; 1 mole, or $44.010 \mathrm{~g}^{2}{ }^{2}$ of carbon dioxide was taken as equivalent to one-fifth mole of these $\mathrm{C}_{5}$ hydrocarbons.

In these experiments, as in the experiments on the $\mathrm{C}_{4}$ hydrocarbons $[1,2]$, in addition to the determination of the mass of water vaporized during the experiment, a determination was usually made of the total mass of water formed during the combustion by flushing the reaction vessel with dry oxygen overnight. From the total masses of water and carbon dioxide, the stoichiometric ratio, $r$, of the number of moles of carbon dioxide to the number of moles of water collected multiplied by the factor $b / 2 a$ or $8 / 10$ (where $\mathrm{C}_{a} \mathrm{H}_{b}$ is the empirical formula of the hydrocarbon) was calculated as described in [2]. The number of experiments, the mean value of $r$, and the standard deviation of the mean for these compounds (except for 1,trans-3-pentadiene) were: 1,2pentadiene (4), $0.99988 \pm 0.00021 ; 1, c i s-3$-pentadiene (4), $1.00003 \pm 0.00013 ; 1,4$-pentadiene (5), 0.99952 $\pm 0.00027 ; 2,3$-pentadiene (4), $1.00007 \pm 0.00019$; 2-methyl-1,3-butadiene (4), $0.99963 \pm 0.00008$; spiropentane (3), $0.99957 \pm 0.00007$. These ratios give additional evidence of complete combustion. In the above calculation, the molecular weights of carbon dioxide and water were taken as 44.010 and 18.0160 , respectively.

Because it is possible that a strong drying agent in the hydrocarbon line might cause isomerization or partial polymerization of these hydrocarbons, most experiments were performed without any drying agent in the line. However, in some of the calorimetric combustion experiments the hydrocarbon vapors were passed through a short length of tubing containing magnesium perchlorate before entering the calorimeter. The results of these experiments did not differ significantly from those run without the drying agent except in the case of 2,3-pentadiene

2 The international atomic weight of carbon has recently been changed from 12.010 [6] to 12.011 [22]. The molecular weight of carbon dioxide was taken as 44.010 in this paper to retain consistency with values previously determined in the Thermochemical Laboratory for the heats of formation of other hydrocarbons the Thermochemical Laboratory for the heats of formation of other hydrocarbons
and of carbon dioxide. The values of the heats of combustion per mole of hydro carbon reported here can be corrected for the effect of the change to the new atomic weight of carbon by multiplication, using the factor 44.011/44.010. 
and of 1,trans-3-pentadiene. In these cases the higher results, obtained with the drying agent in the line and the discoloration of the drying agent in the case of 2,3-pentadiene, indicated that some alteration of the hydrocarbon took place over the drying agent. In these two compounds only the results without drying agent were used in obtaining the mean value.

In none of the compounds, except 1,trans-3-pentadiene, was a significant amount of water vapor carried into the calorimeter with the hydrocarbon vapors, even in those cases where no drying agent was used. This is indicated by the values of the stoichiometric ratios, $r$, given above. In the case of 1,trans-3-pentadiene, the sample was allowed to stand in the bubbler tube in the refrigerator for 2 weeks before use, and some moisture got into the bubbler lines. The stoichiometric ratios, $r$, indicated that in the calorimetric combustion experiments, the following amounts of water vapor were carried into the reaction vessel with the hydrocarbon: $9.20,12.61$, $7.81,3.55$, and $0.48 \mathrm{mg}$ in the experiments 1 to 5 , respectively. The values of the water vaporization corrections, $q_{v}$, were decreased in absolute magnitude by the appropriate amounts, so that, in effect, this water entered and left the calorimeter in the vapor state.

In the course of these experiments, it was discovered that there was an error in the gas correction, $q_{\mathrm{g}}$. Several experiments were run when the room air conditioner was not operating and the room temperature was about $30^{\circ} \mathrm{C}$ instead of near $25^{\circ} \mathrm{C}$. In these experiments it was discovered from the erratic result that $q_{\mathrm{g}}$ overcorrected for the gas energies introduced into the calorimeter. It was presumed that this was due to the fact that the inlet gas temperatures were taken as that of the room, whereas in reality, the inlet tubes pass through a region in which they are affected somewhat by the jacket temperature. By running calorimetric experiments in which only the gases were passed into the calorimeter with different room temperatures, it was found that the proper $q_{\mathrm{g}}$ was obtained when the difference between the room temperature and the calorimeter temperature was multiplied by the factor 0.44 . This correction was applied to all of the experiments reported here and was an appreciable correction, even though in only one of the experiments was the air conditioner not operating. In this experiment (No. 5 on 1,cis-3-pentadiene), the correction was 0.09 percent. The usual magnitude of this correction was about 0.01 percent or less. This indicates that it might be desirable to equilibrate the inlet gases in a coil in the jacket of the calorimeter before leading them into the reaction vessel in the calorimeter.

In the electrical calibration experiments the usual corrections [2] were made for the potentiometer ratio, the loss in the heater leads between the calorimeter and jacket, and the difference in power during the temporary settings of the automatic switch during the first and last (approximately) 3 sec of the heating period. This latter correction, amounting to only about $3 \mathrm{ppm}$, was made more accurately by actually determining the change in current and voltage from the temporary to the permanent settings in separate experiments, rather than calculating it from the different resistances of the paths. This correction could be made completely negligible by making the resistances of the paths through the switch low and equal.

\section{Results}

The results of the electrical calibration experiments are given in table 1. The ground glass joint on the reaction vessel cracked after the experiments on 1,cis-3-pentadiene. Because of necessary repairs, two calorimeter systems were used. System I was used in the experiments on 2-methyl-1,3-butadiene, 1,4-pentadiene, spiropentane, 2,3-pentadiene, and 1,cis-3-pentadiene, and system II on 1,trans-3pentadiene and 1,2-pentadiene. The difference in energy equivalent of the systems agreed satisfactorily with that calculated from the change in mass of the calorimeter parts. System I differed from that last used on the $\mathrm{C}_{4}$ hydrocarbons [2] in that it contained an entirely new calorimeter can; hence, the difference in energy equivalent could not be calculated.

TABLE 1. Electrical calibration experiments

\begin{tabular}{|c|c|c|c|c|}
\hline Experiment & $\Delta R_{\mathrm{c}}$ & $\begin{array}{l}\text { Electric } \\
\text { energy, } E\end{array}$ & $E_{8}$ & $\begin{array}{c}\text { Mean value of } \\
E_{s} \text { with its } \\
\text { standard de- } \\
\text { viation }\end{array}$ \\
\hline \multicolumn{5}{|c|}{ Calorimeter system I } \\
\hline $\begin{array}{l}1 \\
2 \\
3 \\
4 \\
5\end{array}$ & $\begin{array}{c}\text { Ohms } \\
0.393128 \\
.405814 \\
.400331 \\
.370683 \\
.395052\end{array}$ & $\begin{array}{c}j \\
58890.1 \\
60785.7 \\
59967.5 \\
55522.9 \\
59176.7\end{array}$ & $\begin{array}{l}j / \text { ohm } \\
149798.8 \\
149787.1 \\
149794.8 \\
149785.4 \\
149794.7\end{array}$ & $\left\{\begin{array}{c}j / \mathrm{ohm} \\
149792.2 \pm 2.5\end{array}\right.$ \\
\hline \multicolumn{5}{|c|}{ Calorimeter system II } \\
\hline $\begin{array}{l}1 \\
2 \\
3 \\
4 \\
5 \\
6\end{array}$ & $\begin{array}{r}0.395990 \\
.397879 \\
.396393 \\
.394910 \\
.412187 \\
.393411\end{array}$ & $\begin{array}{l}58937.7 \\
59211.4 \\
58999.4 \\
58782.8 \\
61350.5 \\
58558.8\end{array}$ & $\begin{array}{l}148836.3 \\
148817.6 \\
148840.7 \\
148851.1 \\
148841.4 \\
148848.9\end{array}$ & $148839.3 \pm 4.9$ \\
\hline
\end{tabular}

In table 1 are listed: the experiment number; $\Delta R_{c}$, the temperature rise of the calorimeter system corrected for heat transfer to the surroundings and for heat of stirring, expressed as an increase in resistance of the given platinum resistance thermometer on the given resistance bridge; the electric energy, $E$, added to the calorimeter system; and $E_{s}=E / \Delta R_{c}$, the energy equivalent of the system expressed in absolute joules per ohm. The temperature rise was approximately $4 \mathrm{deg} \mathrm{C}$, the initial temperature $23^{\circ} \mathrm{C}$, and the final temperature $27^{\circ} \mathrm{C}$. The jacket temperature was maintained constant at approximately $27.01^{\circ} \mathrm{C}$. 
As a further check on the energy equivalent and the stability of the system, another set of electrical calibration experiments on system II was made a year later. A series of six electrical calibration experiments yielded the mean value $148837.4 \pm 7.5$, which is in excellent agreement with the value in the table, $148839.3 \pm 4.9$.

The results of the calorimetric combustion experiments are given in table 2 , in which are included: the experiment number; the mass of carbon dioxide collected, upon which the amount of reaction was based; $\Delta R_{c}$ in ohms; $q_{g}$, the gas correction; $q_{v}$, the correction for vaporization of water from the calorimeter, which in the case of 1,trans-3-pentadiene includes a reduction in this correction for the water vapor carried into the calorimeter with the hydrocarbon; $q_{i}$, the ignition-energy correction; and $-\Delta H$, the heat of combustion at $25^{\circ} \mathrm{C}$ expressed in absolute joules per gram of carbon dioxide formed where

$$
-\Delta H=\left[E_{s} \Delta R_{c}-q_{g}-q_{v}-q_{i}\right] /\left(\mathrm{gCO}_{2}\right) .
$$

As in the electric-energy experiments, the total energy involved was usually about $59,000 \mathrm{j}$, the temperature rise about $4 \mathrm{deg} \mathrm{C}$, the initial temperature $23^{\circ} \mathrm{C}$, the final temperature usually $27^{\circ} \mathrm{C}$, and the jacket maintained constant at about $27.01^{\circ} \mathrm{C}$.

The ignition energy was determined in separate short-time experiments [2]. The mean ignition energies as determined by such experiments were: 2-methyl-1,3-butadiene, 54.8; 1,4-pentadiene, 45.7; spiropentane, $46.4 ; 2,3$-pentadiene, $49.6 ; 1, c i s-3-$ pentadiene, 44.1 ; 1 ,trans-3-pentadiene, 58.3 ; $1,2-$ pentadiene, $47.9 \mathrm{j}$, all computed to 20 sec of sparking. In separate experiments in which only sparking occurred, the energy was found to be $49.85 \mathrm{j}$ for 20 sec of sparking. The values of $q_{i}$ given in table 2 were computed from the ignition energies given above on the basis of 20 sec of sparking; 49.85/20 j were added for each second of sparking beyond 20 sec, because the sparking was continued for longer periods in many cases to be sure the reaction had started. The values of the ignition energies given above are all close to the sparking energy, $49.85 \mathrm{j}$ for 20 sec of sparking, indicating that the departures of the flame from steady conditions during ignition and extinction and the "blank" corrections to the absorption tubes were small.

TABle 2. Calorimetric combustion experiments

\begin{tabular}{|c|c|c|c|c|c|c|c|c|}
\hline Compound & $\begin{array}{l}\text { Experi- } \\
\text { ment d }\end{array}$ & Mass $\mathrm{CO}_{2}$ & $\Delta R_{\mathrm{c}}$ & $q_{\mathrm{g}}$ & $q_{\mathrm{v}}$ & $q_{\mathrm{i}}$ & $-\Delta H$ at $25^{\circ} \mathrm{C}$ & $\begin{array}{l}\text { Mean value of } \\
-\Delta H \text { with its } \\
\text { standard devia- } \\
\text { tion }\end{array}$ \\
\hline $\begin{array}{l}\text { 2-Methyl-1, } 3 \text {-b ut adiene a (iso- } \\
\text { prene) }\end{array}$ & $\begin{array}{l}1 \mathrm{1} \\
2^{\mathrm{d}} \\
3^{\mathrm{d}} \\
4^{\mathrm{d}} \\
5 \\
6\end{array}$ & $\begin{array}{c}g \\
1.86586 \\
4.12649 \\
4.11258 \\
2.46925 \\
3.86149 \\
3.14389\end{array}$ & $\begin{array}{c}\text { Ohm } \\
0.178616 \\
.396816 \\
.395225 \\
.234347 \\
.370867 \\
.303870\end{array}$ & $\begin{array}{r}j \\
+10.0 \\
-11.2 \\
-12.0 \\
+10.2 \\
-4.4 \\
+4.3\end{array}$ & $\begin{array}{c}j \\
-432.4 \\
-363.4 \\
-389.6 \\
-774.1 \\
-433.3 \\
-482.7\end{array}$ & $\begin{array}{r}j \\
154.5 \\
54.8 \\
54.8 \\
104.7 \\
104.7 \\
453.6\end{array}$ & $\begin{array}{r}j /\left(g \mathrm{CO}_{2}\right) \\
14483.0 \\
14482.0 \\
14479.6 \\
14483.2 \\
14472.7 \\
14485.9\end{array}$ & $14481.1 \pm 1.9$ \\
\hline 1,4-Pentadiene ${ }^{a} \cdots$ & $\begin{array}{l}1 \\
2 \\
3 \\
4 \\
5 \\
5\end{array}$ & $\begin{array}{l}\text { 3. } 22788 \\
\text { 4. } 06198 \\
\text { 3. } 98273 \\
\text { 4. } 00762 \\
2.07938\end{array}$ & $\begin{array}{r}0.313945 \\
.394023 \\
.385675 \\
.388295 \\
.201465\end{array}$ & $\begin{array}{r}+2.9 \\
-11.3 \\
-14.7 \\
-16.3 \\
+7.2\end{array}$ & $\begin{array}{l}-297.0 \\
-427.9 \\
-496.8 \\
-596.3 \\
-426.9\end{array}$ & $\begin{array}{r}108.0 \\
95.6 \\
70.6 \\
195.3 \\
182.8\end{array}$ & $\begin{array}{l}14626.5 \\
14614.8 \\
14616.1 \\
14617.4 \\
14626.9\end{array}$ & $14620.3 \pm 2.6$ \\
\hline Spiropentane ${ }^{a}$.. & $\begin{array}{l}1 \\
2 \\
3^{\mathrm{d}} \\
4^{\mathrm{d}}\end{array}$ & $\begin{array}{l}\text { 3. } 95927 \\
\text { 3. } 94549 \\
\text { 3. } 96727 \\
\text { 3. } 90147\end{array}$ & $\begin{array}{r}0.392446 \\
.391151 \\
.393204 \\
.386683\end{array}$ & $\begin{array}{l}-11.5 \\
-15.2 \\
-15.1 \\
-16.5\end{array}$ & $\begin{array}{l}-576.9 \\
-541.1 \\
-574.0 \\
-550.0\end{array}$ & $\begin{array}{l}58.9 \\
58.9 \\
58.9 \\
58.9\end{array}$ & $\begin{array}{l}14981.2 \\
14976.3 \\
14979.8 \\
14976.3\end{array}$ & $14978.4 \pm 1.2$ \\
\hline 2,3-Pentadiene ${ }^{a_{-}}$ & $\begin{array}{l}1 \\
2 \\
3 \\
4^{\mathrm{d}} \\
5 \\
6\end{array}$ & $\begin{array}{l}\text { 3. } 98516 \\
\text { 3. } 99631 \\
\text { 3. } 82431 \\
\text { 3. } 98980 \\
\text { 3. } 95789 \\
\text { 2. } 82274\end{array}$ & $\begin{array}{r}0.387589 \\
.388957 \\
.372353 \\
.388529 \\
.385356 \\
.274297\end{array}$ & $\begin{array}{l}-10.7 \\
-13.4 \\
-16.7 \\
-19.3 \\
-9.3 \\
-2.9\end{array}$ & $\begin{array}{l}-748.3 \\
-700.8 \\
-655.0 \\
-699.3 \\
-668.4 \\
-574.5\end{array}$ & $\begin{array}{l}62.1 \\
62.1 \\
62.1 \\
59.6 \\
62.1 \\
62.1\end{array}$ & $\begin{array}{c}14743.4 \\
14742.3 \\
14743.9 \\
(14752.0) \\
14739.9 \\
14738.5\end{array}$ & $14741.6 \pm 1.0$ \\
\hline 1,cis-3-Pentadiene ${ }^{a_{-.}}$ & $\begin{array}{l}1 \\
2 \\
3 \\
4^{\mathrm{d}} \\
5^{\mathrm{d}}\end{array}$ & $\begin{array}{l}\text { 4. } 10073 \\
\text { 4. } 09427 \\
\text { 3. } 93324 \\
\text { 4. } 06982 \\
4.10997\end{array}$ & $\begin{array}{r}0.393807 \\
.393134 \\
.377592 \\
.390855 \\
.394952\end{array}$ & $\begin{array}{r}-11.2 \\
+9.0 \\
+3.4 \\
+3.7 \\
+33.1\end{array}$ & $\begin{array}{l}-584.0 \\
-578.6 \\
-596.0 \\
-584.0 \\
-564.5\end{array}$ & $\begin{array}{l}56.6 \\
56.6 \\
56.6 \\
55.6 \\
56.6\end{array}$ & $\begin{array}{l}14516.4 \\
14508.4 \\
14516.4 \\
14514.3 \\
14510.0\end{array}$ & $14513.1 \pm 1.7$ \\
\hline 1, trans-3-Pentadiene $b^{b}$. & $\begin{array}{l}1 \\
2 \\
3 \\
4^{\mathrm{d}} \\
5^{\mathrm{d}}\end{array}$ & $\begin{array}{l}\text { 4. } 09662 \\
4.11379 \\
4.07907 \\
4.06799 \\
2.96571\end{array}$ & $\begin{array}{r}0.395830 \\
.397232 \\
.393948 \\
.393365 \\
.286520\end{array}$ & $\begin{array}{r}-8.4 \\
-12.7 \\
-12.4 \\
-8.1 \\
+6.4\end{array}$ & $\begin{array}{l}\mathrm{c}-475.4 \\
\mathrm{c}-501.4 \\
\mathrm{c}-499.6 \\
\mathrm{c}-525.0 \\
\mathrm{c}-422.2\end{array}$ & $\begin{array}{l}70.8 \\
70.8 \\
70.8 \\
70.8 \\
70.8\end{array}$ & $\begin{array}{c}14482.2 \\
14479.8 \\
14482.7 \\
(14506.1) \\
(14495.8)\end{array}$ & $14481.6 \pm 0.9$ \\
\hline 1,2-Pentadiene $b_{-}$-.. & $\begin{array}{l}1 \\
2 \\
3^{\mathrm{d}} \\
4^{\mathrm{d}} \\
5^{\mathrm{d}}\end{array}$ & $\begin{array}{l}\text { 3. } 99848 \\
\text { 3. } 98360 \\
\text { 3. } 96142 \\
\text { 3. } 98687 \\
\text { 3. } 97958\end{array}$ & $\begin{array}{r}0.393699 \\
.392098 \\
.389955 \\
.392396 \\
.391668\end{array}$ & $\begin{array}{l}+1.2 \\
-3.3 \\
-2.9 \\
-3.2 \\
-2.2\end{array}$ & $\begin{array}{l}-533.4 \\
-560.3 \\
-557.2 \\
-567.7 \\
-569.7\end{array}$ & $\begin{array}{l}60.4 \\
60.4 \\
60.4 \\
60.4 \\
60.4\end{array}$ & $\begin{array}{l}14773.0 \\
14776.3 \\
14777.6 \\
14777.1 \\
14777.2\end{array}$ & $14776.2 \pm 0.8$ \\
\hline
\end{tabular}

a $E_{8}=149792.2 \mathrm{j} / \mathrm{ohm}$.

b $E_{8}=148839.3 \mathrm{j} / \mathrm{ohm}$

c Corrected for the effect of $9.20,12.61,7.81,3.55$, and $0.48 \mathrm{mg}$ of water vapor carried into the calorimeter with the hydrocarbon in the five experiments. d Experiments marked d were run with magnesium perchlorate in the hydrocarbon vapor line. These experiments were included in obtaining the mean for all compounds except 2,3-pentadiene and 1,trans-3-pentadiene (see text). 
TABLE 3. Heats of combustion

\begin{tabular}{|c|c|c|c|}
\hline Compound (gas) & \multicolumn{3}{|c|}{$-\Delta H$ at $25^{\circ} \mathrm{C}$} \\
\hline & $j /\left(g \mathrm{CO}_{2}\right)$ & $k j / m$ & $\mathrm{kcal} / \mathrm{m}$ \\
\hline 1,2-Pentadiene-_. & $14776.2 \pm 2.8$ & $3251.50 \pm 0.62$ & $777.13 \pm 0.15$ \\
\hline 1,cis-3-Pentadiene_....... & $14513.1 \pm 3.9$ & $3193.61 \pm 0.86$ & $763.29 \pm 0.21$ \\
\hline 1,trans-3-Pentadiene.... & $14481.6 \pm 2.9$ & $3186.68 \pm 0.64$ & $761.63 \pm 0.15$ \\
\hline 1,4-Pentadiene & $14620.3 \pm 5.7$ & $3217.20 \pm 1.25$ & $768.93 \pm 0.30$ \\
\hline 2,3-Pentadiene. & $14741.6 \pm 2.9$ & $3243.89 \pm 0.65$ & $775.31 \pm 0.16$ \\
\hline $\begin{array}{l}\text { 2-Methyl-1,3-butadiene } \\
\text { (isoprene) }\end{array}$ & 1448 & $3186.57 \pm 0.96$ & \pm 0.23 \\
\hline Spiropentane & $14978.4 \pm 3.3$ & $3296.00 \pm 0.73$ & $787.76 \pm 0.17$ \\
\hline
\end{tabular}

In table 3 are listed for the seven compounds the values of the heat of combustion, $-\Delta H$, at $25^{\circ} \mathrm{C}$, expressed in joules per gram of carbon dioxide, kilojoules per mole of hydrocarbon (1 mole of hydrocarbon is considered equivalent to 5 moles of carbon dioxide), and kilocalories per mole of hydrocarbon. These values refer to the heat of combustion in the standard calorimetric process. In these experiments, in which approximately three times as much oxygen was used as was needed, the process may be defined by the equation

$\mathrm{C}_{5} \mathrm{H}_{8}\left(\right.$ gas, $\left.1 \mathrm{~atm}, 25^{\circ} \mathrm{C}\right)+21 \mathrm{O}_{2}\left(\right.$ gas, $\left.1 \mathrm{~atm}, 25^{\circ} \mathrm{C}\right)=$ $\left[5 \mathrm{CO}_{2}+14 \mathrm{O}_{2}\right]\left(\right.$ gas, $\left.1 \mathrm{~atm}, 25^{\circ} \mathrm{C}\right)+4 \mathrm{H}_{2} \mathrm{O}(\mathrm{lig}, 1$ atm, $25^{\circ} \mathrm{C}$ ).

The estimated over-all uncertainties assigned to the values given in table 3 were arrived at by the combination of twice the standard deviations of the means of the calorimetric combustion experiments and the electrical calibration experiments, together with an estimated 0.01 percent for uncertainty in electrical measurements and 0.01 percent for uncertainty in the determination of the absolute amount of reaction.

In table 4 are given the values of the heats of combustion, formation, and hydrogenation of these compounds. The standard heat of combustion, $-\Delta H c^{\circ}$, was derived [2] from $-\Delta H$ by taking into account the change in heat content for each gas from its given pressure to zero pressure, so that each substance will have the heat content of the thermodynamic standard state. These heats of combustion refer to the reaction:

$$
\mathrm{C}_{5} \mathrm{H}_{8} \text { (gas) }+7 \mathrm{O}_{2} \text { (gas) }=5 \mathrm{CO}_{2} \text { (gas) }+4 \mathrm{H}_{2} \mathrm{O} \text { (liq) } .
$$

The heats of formation were calculated from the heats of combustion, utilizing the values $68.317 \pm$ $0.010 \mathrm{kcal} / \mathrm{mole}[10]$ and $94.052 \pm 0.011 \mathrm{kcal} / \mathrm{mole}$ [11] for the heats of formation of liquid water and gaseous carbon dioxide, respectively.

The heats of hydrogenation are the heats of hydrogenation to the parent saturated hydrocarbon, $n$-pentane or 2-methylbutane. They were derived by utilizing the values previously reported for the heats of formation of gaseous $n$-pentane and 2methylbutane, $-35.00 \pm 0.16$ and $-36.92 \pm 0.20$ $\mathrm{kcal} / \mathrm{m}$, respectively [12].

In table 5 are given the heats of isomerization of the various isomers to form 2-methyl-1,3-butadiene (isoprene).
TABLE 4. Heats of combustion, formation, and hydrogenation in the gaseous state at $25^{\circ} \mathrm{C}$

\begin{tabular}{|c|c|c|c|}
\hline Compound (gas) & $\Delta H c^{\circ}$ & $\Delta H f^{\circ}$ & $\begin{array}{c}\Delta H^{\circ} \\
\text { hydrogenation }\end{array}$ \\
\hline $\begin{array}{l}\text { 1,2-Pentadiene } \\
\text { 1, cis-3-Pentadiene } \\
\text { 1,trans-3-Pentadiene- } \\
\text { 1,4-Pentadiene.... } \\
\text { 2,3-Pentadiene } \\
\text { 2-Methyl-1, } 3 \text { buta- } \\
\text { diene (isoprene) } \\
\text { Spiropentane. }\end{array}$ & $\begin{array}{l}\text { kcal/mole } \\
-777.14 \pm 0.15 \\
-763.30 \pm 0.21 \\
-761.64 \pm 0.15 \\
-768.94 \pm 0.30 \\
-775.32 \pm 0.16 \\
-761.62 \pm 0.23 \\
-787.77 \pm 0.17\end{array}$ & $\begin{aligned} & \text { kcal } / \text { mole } \\
&+33.61 \pm 0.16 \\
&+19.77 \pm 0.22 \\
&+18.11 \pm 0.16 \\
&+25.41 \pm 0.31 \\
&+31.79 \pm 0.17 \\
&+18.09 \pm 0.24 \\
&+44.23 \pm 0.18\end{aligned}$ & $\begin{array}{c}\text { kcal/mole } \\
-68.61 \pm 0.21 \\
-54.77 \pm 0.25 \\
-53.11 \pm 0.21 \\
-60.41 \pm 0.33 \\
-66.79 \pm 0.21 \\
-55.01 \pm 0.29\end{array}$ \\
\hline
\end{tabular}

TABLE 5. Heats of isomerization to 2-methyl-1,3-butadiene (isoprene)

\begin{tabular}{|c|c|}
\hline Compound (gas) & $\begin{array}{l}\Delta H^{\circ} \text { isomeriza- } \\
\text { tion to isoprene } \\
\text { (gas) at } 25^{\circ} \mathrm{C}\end{array}$ \\
\hline $\begin{array}{l}\text { 2-Methyl-1,3-butadiene (isoprene) } \\
\text { 1,2-Pentadiene } \\
\text { 1, cis-3-Pentadiene- } \\
\text { 1,trans-3-Pentadiene- } \\
\text { 1,4-Pentadiene } \\
\text { 2,3-Pentadiene } \\
\text { Spiropentane }\end{array}$ & $\begin{array}{l}\text { kcal/mole } \\
0 \\
-15.52 \pm 0.23 \\
-1.68 \pm 0.27 \\
-0.02 \pm 0.22 \\
-7.32 \pm 0.34 \\
-13.70 \pm 0.23 \\
-26.14 \pm 0.24\end{array}$ \\
\hline
\end{tabular}

\section{Comparison with Previous Investigations}

Lebedev, Chochlovkin, and Kalacheva [13] determined the heat of combustion of isoprene with an uncertainty of about 1 percent. Their value agrees with the value from the present investigation within this uncertainty.

Jessup [14] determined the heat of combustion of liquid isoprene in a bomb calorimeter. Correction of his value for the new value for the standard heat of combustion of NBS Standard Benzoic Acid, with which he calibrated his calorimeter $\left\{Q_{B}\left(25^{\circ} \mathrm{C}\right)=\right.$ 26433.8 abs $\mathrm{j} / \mathrm{g}[15,16,17]\}$, together with the use of slightly better values for $\Delta C_{p}$ and $p \Delta V$ for the reaction, vields $-\Delta H c^{\circ}\left(25^{\circ} \mathrm{C}\right)=754.9 \pm 0.4 \mathrm{kcal} / \mathrm{mole}$ for liquid isoprene. Taking the heat of vaporization of isoprene as $6.3 \mathrm{kcal} / \mathrm{mole}[23]$ yields $-\Delta H c^{\circ}\left(25^{\circ}\right.$ $\mathrm{C}(=761.2 \pm 0.4 \mathrm{kcal} / \mathrm{mole}$ for gaseous isoprene. This is in good agreement with the value $761.62 \pm 0.23$ $\mathrm{kcal} /$ mole from the present investigation.

Kistiakowsky et al. $[18,19]$ determined the heats of hydrogenation of 1,4-pentadiene and of a mixture of 1,cis-3-pentadiene and 1,trans-3-pentadiene. These data were corrected to a molecular weight of carbon dioxide of 44.010 and from the experimental temperature of $355^{\circ} \mathrm{K}$ down to $298.16^{\circ} \mathrm{K}$ [20]. For 1,4-pentadiene, they obtained $\Delta H h^{\circ}\left(25^{\circ} \mathrm{C}\right)=$ $-60.21 \pm 0.18 \mathrm{kcal} / \mathrm{mole}$, which is in good agreement with the present value of $-60.41 \pm 0.33$ $\mathrm{kcal} / \mathrm{mole}$. For the mixture of 1,cis-3-pentadiene and 1,trans-3-pentadiene, they obtained $\Delta H h^{\circ}\left(25^{\circ}\right.$ $\mathrm{C})=-53.63 \pm 0.18 \mathrm{kcal} / \mathrm{mole}$, which lies between the present values of $-54.77 \pm 0.25 \mathrm{kcal} / \mathrm{mole}$ and $-53.11 \pm 0.21 \mathrm{kcal} / \mathrm{mole}$ for 1, cis-3-pentadiene and 1,trans-3-pentadiene, respectively.

Humphrey and Spitzer [21] determined the heat of combustion of liquid spiropentane in a bomb calorimeter. Their value corrected for the new value of the standard heat of combustion of benzoic acid 
$[15,16,17]$, with which they calibrated their calorimeter, is $-778.8 \mathrm{kcal} / \mathrm{mole}$. Taking the heat of vaporization as $6.6 \mathrm{kcal} / \mathrm{mole}$ [8], their value for the heat of combustion of spiropentane gas, at $25^{\circ} \mathrm{C}$, becomes $-785.4 \mathrm{kcal} / \mathrm{mole}$. This value is not in agreement with the present value of $-787.77 \pm 0.17$ kcal/mole. However, they indicated that the uncertainty in their value was large and that the value should be considered as preliminary.

\section{References}

[1] E. J. Prosen, F. W. Maron, and F. D. Rossini, J. Research NBS 42, 269 (1949) RP1968.

[2] E. J. Prosen, F. W. Maron, and F. D. Rossini, J. Research NBS 46, 106 (1951) RP2181.

[3] F. W. Maron and E. J. Prosen, unpublished data on the heat of combustion of 4-vinyl-1-cyclohexene and the heat of dimerization of 1,3-butadiene.

[4] E. J. Prosen, W. H. Johnson, and F. D. Rossini, J. Am. Chem. Soc. 69, 2068 (1947); 7\%, 626 (1950).

[5] W. H. Johnson, E. J. Prosen, and F. D. Rossini, J. Research NBS 42, 251 (1949) RP1966.

[6] E. Wichers, J. Am. Chem. Soc. 74, 2447 (1952).

[7] A. J. Streiff, L. F. Soule, C. M. Kennedy, M. E. Janes, V. A. Sedlak, C. B. Willingham, and F. D. Rossini, J. Research NBS 45, 173 (1950) RP2122.

[8] D. W. Scott, H. L. Finke, W. N. Hubbard, J. P. McCullough, M. E. Gross, K. D. Williamson, G. Waddington, and H. M. Huffman, J. Am. Chem. Soc. 7\%, 4664 (1950).
[9] M. Shepherd, Anal. Chem. 19, 77 (1947).

[10] D. D. Wagman, J. E. Kilpatrick, W. J. Tavlor, K. S. Pitzer, and F. D. Rossini, J. Research NBS 34, 143 (1945) RP1634

[11] E. J. Prosen, R. S. Jessup, and F. D. Rossini, J. Research NBS 33, 447 (1944) RP1620.

[12] E. J. Prosen and F. D. Rossini, J. Research NBS 34, 263 (1945) RP1642.

[13] S. B. Lebedev, M. A. Chochlovkin, and A. V. Kalacheva, J. Appl. Chem. (USSR) 9, 1605 (1936).

[14] R. S. Jessup, J. Research NBS 20, 589 (1938) RP1093.

[15] R. S. Jessup, J. Research NBS 29, 247 (1942) RP1499.

[16] R. S. Jessup, J. Research NBS 36, 421 (1946) RP1711.

[17] Announcement of changes in electrical and photometric units, NBS Circular 459 (U. S. Government Printing Office, Washington 25, D. C., 1948) price 5c.

[18] G. B. Kistiakowsky, J. R. Ruhoff, H. A. Smith, and W. E. Vaughan, J. Am. Chem. Soc. 58, 146 (1936).

[19] M. A. Dolliver, T. L. Gresham, G. B. Kistiakowsky, and W. E. Vaughan, J. Am. Chem. Soc. 59, 831 (1937).

[20] J. E. Kilpatrick, C. W. Beckett, E. J. Prosen, K. S. Pitzer, and F. D. Rossini, J. Research NBS 42, 225 (1949) RP1964.

[21] G. L. Humphrey and R. Spitzer, J. Chem. Phys. 18, $902(1950)$.

[22] E. Wichers, J. Am. Chem. Soc. 76, 2033 (1954).

[23] N. Bekkedahl, L. A. Wood, and M. Wojciechowski, J. Research NBS 1\%, 883 (1936) RP951.

Washington, December 7, 1954 . 